\title{
Working
}

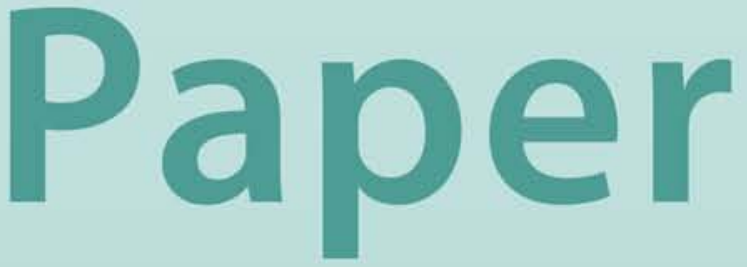


A Game-Theoretic Analysis of Corruption in Bureaucracies

Era Dabla-Norris 


\title{
IMF Working Paper
}

Fiscal Affairs Department

\section{A Game-Theoretic Analysis of Corruption in Bureaucracies}

\author{
Prepared by Era Dabla-Norris ${ }^{1}$ \\ Authorized for distribution by Liam Ebrill
}

June 2000

\begin{abstract}
The views expressed in this Working Paper are those of the author(s) and do not necessarily represent those of the IMF or IMF policy. Working Papers describc research in progress by the author(s) and are published to elicit comments and to further debate.
\end{abstract}

This paper examines interactions between self-interested agents in a two-tier government hierarchy, consisting of a central authority and bureaucrats in a two-stage game, where the actions of agents affect private sector allocations. Conditions under which lower-tier corruption arises as an equilibrium characterization of the game are identified. If bureaucratic corruption sufficiently reduces the tax base, policies that deter corruption may be optimal. When monitoring is expensive or ineffective, lower-level corruption arises as equilibrium. Tax farming and the sale of offices can occur in these equilibria. In addition, strategic complementarities between bureaucrats may give rise to multiple equilibria.

JEL Classification Numbers:C72, D23, D73

Keywords: Corruption, hierarchies, multiple equilibria

Author's E-Mail Address: edablanorris@imf.org

\footnotetext{
${ }^{1}$ The author wishes to thank Maxwell Stinchcombe for comments on an earlier version of the paper.
} 


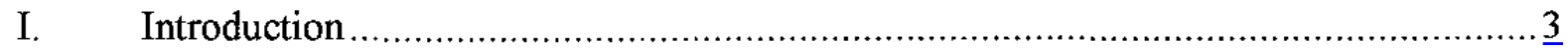

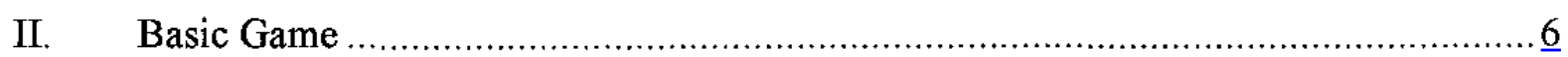

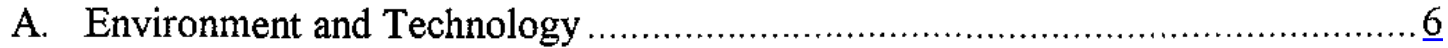

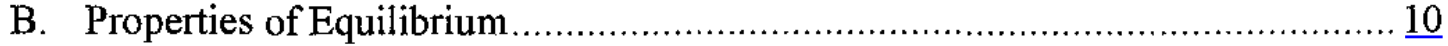

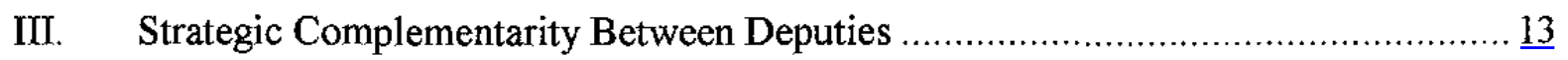

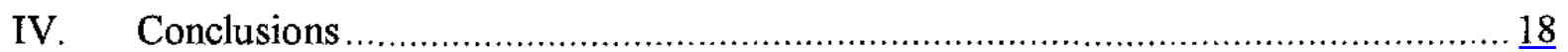

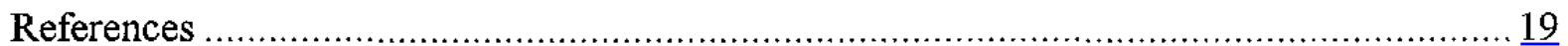




\section{INTRODUCTION}

A fundamental role of the state lies in its provision of a legal order, in its ability to implement and enforce property rights and other formal rules in an economy, thereby enhancing economic activity. ${ }^{1}$ However, individuals that make up the state apparatus, often abuse this power to appropriate the surplus generated from private economic activity. ${ }^{2}$ Governmental corruption can be viewed as one such abuse of authority.

Corruption by government officials encompasses a broad class of abuses. They range from bribe taking in the provision of public goods, such as licenses and permits to malfeasance in tax collection, to corruption in the enforcement of commercial agreements, to tax farming, and even outright expropriation. Examples of such practices abound in many developing countries (see Tanzi, 1998). The pervasiveness of governmental corruption in many developing countries today, however, does not imply that this phenomenon is confined to these countries. The sale of public offices and the pervasiveness of tax farming in ancient Rome and in seventeenth century Europe are important historical instances of corruption in developed countries.

Casual empiricism and country studies suggest that corruption distorts the allocation of resources and discourages investment. Recent cross-country studies also find that the level of corruption is negatively associated with economic growth (see Mauro, 1995 and Keefer and Knack, 1993). It is easy to see how corruption discourages private sector activity, thereby, constraining a state's capacity to tax its constituents. A more difficult question is why any self-interested, revenue maximizing state, knowing the consequences, would permit widespread corruption among its agents? Casual observation suggests that there is significant variation in the nature and degree of corruption both across countries and across time, even for similar activities. For example, the level of corruption in many present day developed countries is much lower today than was the case historically. What accounts for this variation in the form and levels of corruption? A related question is why does the incidence of corruption vary across otherwise similar countries (e.g., between seventeenth century France and England) or regions within the same country?

Corruption in many developing and transition countries results from a combination of opportunities and incentives. Opportunities for abuse of power are prevalent in discretionary areas of government policy. For instance, complex tax and customs systems, capital controls and financial market regulation, wide-ranging regulations on the private sector, privatization decisions, and discretion over allocation of public expenditure can

\footnotetext{
${ }^{1}$ The formal rules governing the extraction of revenue, enforcement of contracts, etc.

${ }^{2}$ This view of the state is nested in the neoclassical political economy's approach to the state as a self-interested actor (Bardhan, 1990 and Olson, 1990) that enforces property rights and contracts (North, 1990 ) but can take advantage of its monopoly power to engage in predatory behavior designed to extract revenue (Levi, 1988) or otherwise acquire rents (Srinivasan, 1985) from the population.
} 
create room for corruption. ${ }^{3}$ Lack of transparency and of effective institutional controls are commonly viewed as the main factors contributing to corruption. Incentives to engage in corrupt behavior include lack of meritocratic recruitment and promotion in civil service, weak legal enforcement, low government salaries, poor systems of accounting and auditing, a general lack of transparency in government operations, and the absence of well-developed "civil society" institutions. Many of these factors are, in turn, closely associated with the level of development of an economy. For instance, eradication of corruption may be costlier in countries where the level of institutional development and the general economic environment is weak. ${ }^{4}$

In this paper, we analyze strategic interactions between opportunistic and self-interested agents at different levels of a government hierarchy in a two-stage game. ${ }^{5}$ The general approach is to examine the behavior of these agents and its effect on the underlying level of real economic activity in order to characterize conditions under which governmental corruption can occur as an equilibrium phenomenon. The game we set up is extremely simple: there are three types of agents - a central authority or dictator, deputies, and private agents. The actions of the dictator and deputies influence private sector allocations, in particular, the decisions of private agents to engage in productive or investment activity. Deputies are needed to provide an important service that affects market activity, which provides the tax base for the dictator. ${ }^{6}$ The dictator supervises the deputies' activities by providing monitoring effort and wage incentives, and has the ability to tax aggregate market activity.

Deputies are assumed to enjoy some discretion in their job that they can misuse for private gain. The type of corruption we have in mind is the abuse of their power over public commerce to solicit bribes from private agents or otherwise expropriate market activity. $^{7}$ The dictator can make use of his regulatory powers over deputies (through his choice of monitoring effort and wage rates) and private economic activity (through his choice of tax policy) to independently create rents for himself. Actions of deputies are assumed to be costly to monitor, creating a standard agency problem. Finally, the sequencing of actions is as follows: the dictator first chooses his policy instruments, given which, individual deputies decide upon their own actions and the optimal level of private sector activity is determined.

\footnotetext{
${ }^{3}$ See Tanzi (1998) for a description of areas where opportunity for corruption may arise as a result of excessive government regulation and discretion in the provision of goods and services in the economy.

${ }^{4}$ Dabla-Norris and Freeman (1999) develop a model of the interconnectedness of underdevelopment and corruption, in which pervasive corruption discourages market activity, thereby, reducing the incentives to allocate resources for controlling corruption.

${ }^{5}$ The term government hierarchy and the state will be used interchangeably in this paper.

${ }^{6}$ For instance, the provision of public goods, such as licenses, permits, and import quotas to producers; collection of duties on legal imports by customs inspectors; the settlement of disputes between private agents, etc.

7'This is akin to Shliefer and Vishny's (1993) notion of "public rent-seeking", which they define as a redistribution from the private sector to government bureaucrats who can influence private economic activity.
} 
This relatively simple framework provides a rich set of predictions that fit the observed patterns of corruption and anticorruption policy in many countries. First, it shows that the self-interest of a central authority can induce the dictator to provide incentives to eliminate corruption at the lower level of the hierarchy. ${ }^{8}$ Hence, corruption arises when the dictator chooses against making a commitment to deter it. The analysis also provides a number of predictions about the determinants of corruption. In particular, we show that corruption is more likely to arise where supervision is ineffective, monitoring costs are high, wage incentives costly, and the tax apparatus weak. Many of these factors are more likely to exist in developing and transition economies. Therefore, as noted by Levi (1988), reductions from historically high levels of corruption in present day developed countries may reflect improvements over time in monitoring and supervision technologies or reductions in the costs of providing proper incentives.

The existence of low public sector wages is frequently cited as an important cause of bureaucratic corruption in many developing countries. ${ }^{9}$ This however begs the question of why the government sets salaries which are so low. Our model explains why the central authority may choose to allow corruption in a wide variety of situations. We show that if monitoring is ineffective and costly, central authorities may economize on the costs of providing efficiency wages by allowing corruption to take place. Further, we show that, under certain conditions, it may even be optimal for the dictator to sell the office of a deputy (tax farming), thereby, recouping some of the illicit gains accruing to the deputies. ${ }^{10}$

The underlying idea is that by not rigorously enforcing rules or even encouraging corruption, the central authority offers its deputies "implicit contracts" with provisions that go well beyond the provisions of formal contracts. In particular, if there are substantial administrative costs to providing monitoring or wage incentives, this implicit part of the contract-that is, corrupt activities to which one turns a blind eye-can be far more lucrative (in terms of revenue raised for the central authority) than the official part, and may be a part of a larger political spoils scheme. ${ }^{11}$

Finally, we show that in the presence of strategic complementarities, multiple equilibria may arise even if the central authority can set levels of bureaucratic monitoring and wages. ${ }^{12}$ In particular, we show that with costly or ineffective monitoring, there can be

\footnotetext{
${ }^{8}$ This result is akin to Olson's (1993) idea that a self-interested ruler with an "encompassing" interest in the domain over which his coercive power is exercised can be lead to act in ways that are consistent with those subject to that power.

${ }^{9}$ In a cross-country regression van Rijckeghem and Weder (1997) find that countries with poorly paid public officials tend toward greater corruption.

${ }^{10}$ See Wade (1982) for a description of sale of offices associated with the rights to allocate irrigation water in southern India.

${ }^{11}$ In her study of revenue production in Republican Rome, Margaret Levi (1988) notes that high measurement, monitoring, and delegation costs were responsible for the rise of tax farming as a means of securing revenue for the state.

${ }^{12}$ In this context, strategic complementarity refers to the increasing profitability of engaging in corrupt acts when all others are acting in the same way. For example, an increase in the number of corrupt agents
} 
two subgame-perfect equilibria in the game: one characterized with a level of high corruption and a low level of private sector activity; the other with a low level of governmental corruption and a high level of economic activity, as in Dabla-Norris and Freeman (1999) and Shliefer and Vishny (1995). This multiplicity of equilibria suggests that identically endowed economies can end up with very different outcomes.

This paper relates to the growing literature on corruption. Mookherjee and Png (1995), Besley and McLaren (1993), Banerjee (1997), and Acemoglu and Verdier (1998) develop models where corruption arises due to agency problems. Each of these papers, however, ignores the possibility of multiple equilibria in the presence of efficiency wages. More importantly, our paper differs from most of the literature in its level of generality. While other papers tell stories related to particular situations where corruption may arise, the present paper has the advantage of capturing a wide variety of situations in which corruption can occur.

The remainder of the paper proceeds as follows. In Section 2, we describe a general game in which each deputy acts independently of the other deputies in the hierarchy and characterize some important properties of its equilibrium set. In Section 3 , we extend this game to allow for strategic interactions between deputies and describe the general properties of a game in this environment. Section 4 concludes.

\section{BASIC GAME}

\section{A. Environment and Technology}

In the analysis that follows, we assume that the size of the second tier of the government hierarchy is fixed and equal to a continuum of measure one. We describe a game in which each deputy acts independently of the other deputies in the hierarchy. The decision variable of each deputy $i \in[0,1]$, is a level of corruption $c_{i} \in C_{i}=[0,1]$, where $c_{i}=0$ denotes perfect honesty. Let $x \in[0,1]$ denote the level of private sector activity in the econorny. ${ }^{13}$ Let $w \in \mathbb{R}$ denote the wage received by each deputy $i$ in the public sector, where $w<0$ denotes a transfer from deputy $i$ to the dictator. Finally, let $e$ denote the enforcement effort chosen by the dictator to monitor a deputy, where, $e$, by assumption, affects all deputies identically. The preferences of deputy $i$ are represented by a utility function $V_{i}$ that depends on $w, e, c_{i}$, and $x$, where $V_{i}: \mathbb{R} \times[0,1] \times[0,1] \times[0,1] \longrightarrow \mathbb{R}$. Let $\bar{V}$ denote the reservation utility of a deputy.

may raise the cost of an effective audit as in Lui (1986), thereby, reducing the chance that each will be caught or the severity of punishment upon detection may decline as more officials are corrupt, thus, increasing the payoff from engaging in corruption.

${ }^{13}$ If we interpret economic activity to denote aggregate investment in the economy, then $x$ can be regarded as the aggregate of investment decisions. Alternatively, $x$ can be regarded as the aggregate decision whether or not to engage in productive market activity. 
Assumption A 1. $V_{i}\left(c_{i}, x, e, w\right)$ is continuous in its arguments, increasing in $w$, and $x$ and decreasing in $e . \forall x, w$ there exists an $e^{\circ}>0$ such that $V$ is increasing in $c_{i}$ for $e<e^{\circ}$ and $V$ is decreasing in $c_{i}$ for $e>e^{\circ}$.

The first part of A1 states that the utility from being a deputy is increasing in the wage rate received in the public sector and in the level of private economic activity. The latter condition captures the idea that the payoff to a deputy is increasing in the level of economic activity under his control. The assumption that $V(\cdot)$ is decreasing in $e$ implies that a higher level of monitoring effort reduces the utility obtained by a deputy. To see this, suppose that, for all $c_{i}>0$, each deputy faced a probability of apprehension that was increasing in the dictator's monitoring effort. Then, this condition would hold if the expected utility to a deputy when apprehended was lower than his expected utility from not being apprehended (say, because he is fired). The last condition implies that there is a positive level of monitoring effort above which a deputy's utility is decreasing in his level of corruption. ${ }^{\mathbf{1 4}}$ In terms of our earlier example, this would be the case if, for all $e>0$, the probability of apprehension faced by a deputy was increasing in his level of corruption; and the greater the dictator's monitoring effort, an increase in $c_{i}$ caused a greater increase in the probability with which a deputy is apprehended.

Notationally, a deputy's best response is

\section{Definition 1.}

$$
c_{i}^{*}(x, w, e) \in \arg \max _{c_{i} \in[0,1]} V_{i}\left(c_{i}, x, e, w\right)
$$

Given that $c \in[0,1]$, assumption 1 implies that, for all $x$ and $w$, a deputy's best response is to be honest if $e>e^{\circ}$ and to be corrupt if $e<e^{\circ}$. Formally,

$$
\begin{array}{ccc}
c_{i}^{*}=0 & \text { for } & e>e^{\circ} \\
c_{i}^{*} \in[0,1] & \text { for } & e=e^{\circ} \\
c_{i}^{*}=1 & \text { for } & e<e^{*} .
\end{array}
$$

A deputy's best response correspondence is, therefore, discontinuous at $e=e^{\circ}(x, w)$. This discontinuity implies that a deputy is indifferent between corruption and honesty at that level of enforcement. We make the following assumption about $e^{\circ}(x, w)$

Assumption A 2. $e^{\circ}(x, w)$ is continuous in its arguments, nondecreasing in $x$ and nonincreasing in $w$.

The assumption that $e^{\circ}(w, e)$ is nondecreasing in $x$ captures the idea that a deputy's incentive to be corrupt is increasing in the amount of private sector activity he can appropriate for himself, either in the form of higher bribes or outright expropriation. The level of monitoring effort for which a deputy chooses perfect honesty is therefore

\footnotetext{
${ }^{14}$ Note that this assumption is satisficd by expected utility maximization.
} 
(weakly) increasing in the level of economic activity. Similarly, the assumption that $e^{\circ}$ is nonincreasing in $w$ implies that there is tradeoff between the wage rate offered in the public sector and the level of monitoring effort required to ensure honesty at the lower tier. The intuition is that a higher public sector wage also deters corruption by raising the opportunity cost of loosing one's job when corruption is detected and punished, thus inducing the deputy to be less corrupt. The level of private sector activity in the economy is represented by a reduced form function $x^{*}(c, \tau) \in X=[0,1]$. The function $x:[0,1] \times[0,1] \longrightarrow[0,1]$, relates the level of economic activity to the average level of corruption $c$ in the economy, where $c=\int_{i=1}^{1} c_{i} d i$, and the tax rate, $\tau \in[0,1]$, set by the dictator. ${ }^{15}$ Note that the return on economic activity is a function of the average level of corruption in the economy, $c$, and not the level of corruption of any given deputy, $c_{i}$. Given that all deputies are assumed to be identical, however, the average level of corruption in the economy is identical to the level of corruption of any given deputy. Let $x_{i}^{*}$ denote the optimal level of private sector economic activity. We make the following assumptions about $x_{i}^{*}$ :

Assumption A 3. $x_{i}^{*}(c, \tau)$ is continuously differentiable in its arguments and decreasing in $c$ and $\tau$.

A3 implies that a higher tax rate and a higher average level of corruption in the economy, both, result in a lower level of economic activity. The assumption that high tax rates have a disincentive effect on market activity is fairly standard. In our analysis, however, bureaucratic corruption is also assumed to discourage economic activity. The idea is that, as in the case of taxation, economic activity is reduced through a decline in the expected return on investment or productive activity due to a higher threat of expropriation. ${ }^{16}$ Finally, the dictator's decision variables is the vector of policy instruments $(w, e, \tau)$. Let $U(w, e, \tau ; x)$ denote the utility function of the dictator The function $U: \mathbb{R} \times[0,1] \times[0,1] \times$ $[0,1] \times[0,1] \times[0,1] \longrightarrow \mathbb{R}$ is assumed to satisfy the following properties:

Assumption A 4. $U(w, e, \tau ; x)$ is continuously differentiable in its arguments, decreasing in $w$ and $e$, and increasing in $\tau$, and $x$.

The assumption that $U(\cdot)$ is decreasing in $e$ and $w$ implies that there are costs to the dictator of providing incentives for the deputies. For instance, if monitoring costs are

\footnotetext{
${ }^{15}$ We are assuming that the dictator can precommit to a preannounced tax rate. The failure of a dictator who exercises sovereign power to irrevocably commit himself to a preannounced tax rate has been discussed elsewhere in the literature. See, for example, Grossman and Noh (1990).

${ }^{16}$ As in Banerjee (1997) and Acemoglu and Verdier (1996), corruption can be thought of as deterring ex ante incentives to invest because ex post individuals do not reap the full benefits of such investment. This assumption is consistent with recent empirical findings on the links between bureaucratic corruption and investment. For instance, both, Mauro (1995) and Keefer and Knack (1995) find that bureaucratic corruption is negatively correlated with private investment and growth.
} 
increasing in effort, increases in $e$ may translate into a lower level of utility for the dictator. Similarly, if the number of deputies in the public sector is large, higher wages may reduce the dictator's utility by raising his total wage bill. In a general sense, therefore, this assumption captures the idea that prevention of corruption is costly. Finally, the assumption that the dictator's utility is increasing in $\tau$ and $x$ reflects the idea that his tax revenues are increasing in his tax rate and in the level of economic activity. Note that this specification of the dictator's utility function implicitly assumes that "lower tier" corruption only affects his utility indirectly through its effect on the level of private sector activity. ${ }^{17}$

To complete the specification of this game, we define $\tilde{w}$ as the reservation wage offered by the dictator.

Definition 2. $\tilde{w}(e, \tau, \bar{V}) \equiv \inf \left\{w: V\left(e, w, x^{*}, c^{*}\right) \geq \bar{V}, x^{*}=x^{*}\left(c^{*}, \tau\right), c^{*}=c^{*}\left(x^{*}, e, w\right)\right\}$

The above definition implies that $\forall e, \tau, \bar{V}$ if $w \geq \tilde{w}(e, \tau, \bar{V})$, all deputies are at least as happy being deputies as pursuing outside options. The wage offered by the dictator, therefore, lies in the interval $[\tilde{w}, \infty)$. Let $\Gamma=\Gamma\left(X, U, V_{i \in[0,1]}\right)$ define a game in this environment. The equilibrium notion we use is that of a perfect equilibrium. We therefore assume that at each move, each agent chooses so as to maximize its utility and takes into account that in the subsequent moves everyone will choose so as to maximize their utility. An outcome that emerges from such a sequence of decisions is referred to as a Stackelberg perfect equilibrium. Formally, we define

Definition 3. A Stackelberg perfect equilibrium for $\Gamma\left(X, U, V_{i \in[0,1]}\right)$ is a quintuple $\left(e^{*}, w^{*}, \tau^{*}, c^{*}, x^{*}\right)$ satisfying

1. $x^{*}=x^{*}\left(c^{*}, \tau^{*}\right)$,

2. $c^{*}=c^{*}\left(x^{*}, e^{*}, w^{*}\right)$,

3. $\left(w^{*}, e^{*}, \tau^{*}\right) \in \arg \max _{w, e, \tau} U\left(w, e, \tau, x^{*}\right)$.

Theorem 1. Under Assumptions $A 1-A 4, \Gamma\left(X, U, V_{i \in[0,1]}\right)$ has an equilibrium.

Proof: Without loss of generality, one may assume that $w$ is in a bounded interval $[\tilde{w}, W] .{ }^{18}$ The dictator then chooses a vector of actions, $a=(w, e, \tau)$ from the dictator's compact set $A=[\tilde{w}, W] \times[0,1] \times[0,1]$. The equilibria of this game correspond to solutions

${ }^{17}$ This assumption does not restrict the ability of our model to explain how corruption propagates in the government hierarchy. We capture the recursive property of corruption by assuming that the dictator can extract rents from those below him in the hierarchy by setting $w<0$.

${ }^{18}$ Although the dictator can, in principle, select any wage rate above $\tilde{w}$, there are wage rates so high that they cannot, under any circumstances, be optimal. Thus $W$ can be regarded as the largest wage rate that satisfies the dictator's budget constraint. 
of the following maximization problem:

$$
\begin{aligned}
& \max _{w, e, \tau} U\left(w, e, \tau ; x^{*}\right) \\
& \text { subject to } \\
x^{*}= & x^{*}\left(c^{*}, \tau\right) \\
c^{*}= & c^{*}\left(x^{*}, e, w\right)
\end{aligned}
$$

The constraints define a closed nonempty subset of $A$. Given that $U$ is continuous, a maximum exists.

\section{B. Properties of Equilibrium}

Let $E(\Gamma)$ denote the set of all equilibria of this game. ${ }^{19}$ We now turn to the characterization of some properties of the equilibrium set, $E(\Gamma)$. The first result characterizes conditions on the dictator's optimal choice of policy instruments such that all deputies choose corruption or honesty, respectively. Define the vector of policy actions of the dictator for which each deputy's best response is to either be corrupt or perfectly honest as follows:

\section{Definition 4.}

$$
\begin{aligned}
& B \equiv\left\{(w, e, \tau): c^{*}\left(e, w, x^{*}\right)=1, x^{*}=x^{*}(1, \tau), w \geq \tilde{w}\right\} \\
& D \equiv\left\{(w, e, \tau): c^{*}\left(e, w, x^{*}\right)=0, x^{*}=x^{*}(0, \tau), w \geq \tilde{w}\right\}
\end{aligned}
$$

$B$ and $D$ define sets whose typical elements are a vector of policy actions such that deputies choose corruption or perfect honesty, respectively. and the participation constraints of deputies are satisfied. The following lemma provides us with conditions that the set of policy instruments chosen by the dictator must satisfy in an equilibrium with perfect honesty or corruption, respectively.

\section{Lemma 1.}

(1) There exists $(w, e, \tau) \in E(\Gamma)$ s.t. $c^{*}=0$ iff $\sup _{b \in B} U(b) \geq \sup _{d \in D} U(d)$.

(2) There exists $(w, e, \tau) \in E(\Gamma)$ s.t. $c^{*}=1$ iff $\sup _{b \in B} U(b)<\sup _{d \in D} U(d)$.

Proof: Follows from the definition of equilibrium (definition 2.3) and definition of the sets $B$ and $D$ (definition 2.4). Lemma 2.1. states that the dictator's choice of policy instruments, for which perfect honesty or corruption, respectively, are best responses, depend upon the payoffs attainable to him from that set of policy actions relative to another. Perfect honesty at the lower level of the hierarchy, therefore, requires that the

\footnotetext{
${ }^{19}$ Note that there are only pure strategy equilibria in this game.
} 
payoff to the dictator from choosing a policy mix that induces honesty exceed his payoff from any other policy alternative. An important implication of this result is that the selfinterest of a dictator can induce him to adopt policies that ensure honesty at the lower levels of the government hierarchy. Moreover, in light of the assumption that economic activity is decreasing in lower level corruption (assumption A3) and the assumption that the dictator's utility is increasing in the level of economic activity (assumption A4), Lemma 2.1 suggests that a self-interested, opportunistic dictator can, in effect, act as if he has an equity stake in economic activity.

In general, however, the existence of this result depends upon the responsiveness of economic activity to the level of corruption in the economy, monitoring costs, the effectiveness of monitoring effort in controlling lower level corruption, the administrative costs of providing wage incentives, and the efficiency of the tax apparatus. Intuitively, an equilibrium with perfect honesty is more likely to exist if economic activity is very responsive to corruption, the costs of providing monitoring and wage incentives are low, and economic activity is not very responsive to the dictator's choice of a tax rate.

In what follows, we characterize conditions under which the dictator chooses to monitor deputies. As discussed earlier, the best response of a deputy is to be honest $\forall e \geq$ $e^{\circ}(x, w)$. By assumption $\mathrm{A} 4, U(\cdot)$ is decreasing in $e$. From assumption $\mathrm{A} 1, e^{\circ}$ can be regarded as the smallest level of monitoring effort of the dictator for which each deputy chooses to be perfectly honest, for all $x$ and $w$. Note that the sequence of actions in this game implies that the dictator can commit to a level of monitoring before the deputies have an opportunity to act. Therefore, $e^{\circ}$ can be regarded as the minimum level of monitoring to which a dictator must precommit. ${ }^{20}$ The following proposition characterizes the equilibrium precommitment of monitoring effort by the dictator.

\section{Proposition 1.}

(1) If $c^{*}=0$ in equilibrium, then $e^{*}>0$

(2) If $c^{*}=1$ in equilibrium, then $e^{*}=0$.

Proof: Follows from assumption A1, the definition of equilibrium and definition 2.5. Condition (1) states that in an equilibrium with perfect honesty, the dictator commits a

positive amount of monitoring effort to deter corruption. Condition (2) implies that an equilibrium with corruption arises if the dictator gives up on monitoring effort. To see this, suppose that the dictator chooses a level of monitoring such that there is a positive level of lower tier corruption. From assumption A1 and definition 2.1, we know that the level of monitoring effort chosen by the dictator, $e^{*}$ must be less than $e^{\circ}$. Given that for all $e<e^{\circ}, c^{*}=1$ (from assumption $\mathrm{A} 1$ ), the dictator is best off reducing monitoring effort to zero, since, by assumption $\mathrm{A} 4$, monitoring is costly.

\footnotetext{
${ }^{20}$ We can interpret $e$ as the effort by the dictator to install legal infrastructure or auditing procedures in the hierarchy to deter lower level corruption.
} 
The intuitive argument behind Proposition 2.1 is clear: if corruption is not to be deterred, the dictator has no incentive in making a costly commitment. Hence, $e^{*}=0$. If corruption is deterred, the dictator is expending effort to control corruption with the monitoring effort necessary to deter corruption. Hence, the dictator sets $e^{*}=e^{0}>0$. In general, the existence of this result depends upon monitoring costs, the effectiveness of monitoring effort in reducing corruption and the responsiveness of economic activity to corruption. For example, if the dictator's utility is increasing in private sector activity, as is assumed in A4, he may precommit to a positive level of monitoring effort if a higher level of corruption in the economy reduces his total payoffs. Intuitively, an equilibrium with lower level corruption and zero monitoring is more likely to exist when monitoring costs increase sharply in effort, the probability of apprehending corrupt deputies is sufficiently inelastic, and economic activity is not very responsive to bureaucratic corruption.

An important implication of proposition 2.1 is that if corruption is not deterred, then for any given tax rate, $\tau$, and reservation utility for a deputy, $\bar{V}$, the dictator is best off choosing the lowest wage that satisfies each deputy's participation constraint. Let $w^{\circ}$ define the smallest wage offered by the dictator if he precommits nothing, that is $e=0$

Definition 5. $w^{\circ}(\tau, \bar{V}) \equiv \inf \left\{w: V\left(0, w, x^{*}, c^{*}\right) \geq \bar{V}, x^{*}=x^{*}\left(c^{*}, \tau\right), c^{*}=c^{*}\left(x^{*}, 0, w\right)\right\}$

The above condition implies that for $e=0$, and $\forall \tau \bar{V}, w^{\circ} \geq \tilde{w}(0, \tau, \bar{V})$.

Corollary 1. If $c^{*}=1$ in equilibrium, then $w^{*}=w^{\circ}$

This result follows directly from Lemma 2.1, definition 2.6 and the assumption that the dictator's payoff is decreasing in the public sector wage (assumption A4). The intuitive reasoning behind this result is clear. In the absence of monitoring, forall $x$ and $w$, the optimal level of lower level corruption is one. In light of the assumption that economic activity is decreasing in the level of lower tier corruption (assumption A3), for any given $\tau$, total revenues $(\tau x)$ for the dictator fall. If the provision of public sector wages is costly, as is assumed in this game, the administrative cost of providing wage incentives may exceed tax revenues. As a result, in the absence of monitoring, the optimal strategy for the dictator will always be to choose the lowest wage rate that satisfies deputies' participation constraints.

One consequence of this result is that if deputies are not liquidity constrained, the dictator may extract some (and perhaps all) of the corrupt rents that accrue to deputies by setting a fixed fee for the office of a deputy (say, by setting $w^{*}<0$, where $w^{*} \geq \tilde{w}(0, \tau, \bar{V})$ ). Moreover, in the absence of effective monitoring, if the specific source of bureaucratic inefficiency is corruption by tax collectors, then selling the office of a tax collector may be a preferred regime from the point of view of tax revenues raised. Tax farming in this context refers to a situation where deputies bid for the rights to collect taxes, paying a specified sum before collection, and buying the right to pocket the surphus collected from taxpayers. The use of tax farming as a means to raise revenues, however, depends on the responsiveness of economic activity to bureaucratic corruption, since a higher level 
of taxation by rapacious bureaucrats may result in a lower aggregate level of revenues raised for the dictator. ${ }^{21}$

\section{STRATEGIC COMPLEMENTARITY BETWEEN DEPUTIES}

In this section, we analyze a game in which the optimal action of a deputy is an increasing function of the actions of other deputies in the hierarchy. ${ }^{22}$ In particular, we make the assumption that the optimal level of corruption chosen by a deputy is an increasing function of the level of corruption chosen by other deputies in the public sector (so that the game exhibits strategic complementarity). ${ }^{23}$ Introducing such strategic interactions between deputies allows us to capture a fundamental observation on corruption: the expected profitability of engaging in corrupt acts depends crucially on the behavior of others acting in the same way.

For deputy $i$, let $\hat{c}=\int_{0}^{1} c_{j} d j$ denote the average level of corruption of all deputies other than $i$. The preferences of deputy $i$ are now represented by a function $V_{i}\left(c_{i}, \hat{c}, x, e, w\right)$, where the payoff to deputy $i$ is assumed to be a function of the average level of corruption of other deputies in the economy. The literature on corruption emphasizes the external benefits inherent from engaging in corrupt activity. For example, it may become very costly to audit officials when a greater proportion of them become corrupt, or the expected probability of being punished when detected may decline with the general level of corruption in the civil service. We capture this observation using the following assumption:

Assumption A 5. $V_{i}$ is continuously increasing in $\hat{c}$, for all other variables.

Assumption A5 captures the idea that an increase in the strategy of all but one deputy bestows an external benefit, or a positive externality, on the remaining agents. ${ }^{24}$

In Section 2.1, we assumed that a deputy's payoff is decreasing in his level of corruption for a fixed level of monitoring effort, $e^{\circ}$ (Assumption A1). We now modify this assumption by making the enforcement effort targeted toward a given deputy be a function of the level of corruption of other deputies in the economy. Formally,

Assumption A 6. For a given $\hat{c}$, there exists $\tilde{e}(\hat{c})$ such that $V_{i}$ is decreasing in $c_{i}$ for $e>\tilde{e}(\hat{c})$ and increasing in $c_{i}$ for $e<\tilde{e}$; further, $\tilde{e}(\cdot)$ is increasing in $\hat{c}$

\footnotetext{
${ }^{21}$ In general, a dictator's proclivity for regulating tax farming is likely to be related to his security of tenure. A government run by a succession of self-interested central authorities, with the short horizons inevitable given their insecurity of tenure, would have a greater propensity to engage in tax farming than a more stable government.

${ }^{22}$ The class of games that satisfy this property are called "supermodular" games. For an analysis of supermodular games see Topkis (1979). See also Milgrom and Roberts (1990) for other economic applications of games that exhibit supermodularity.

${ }^{23}$ The term "strategic complements" was introduced by Bulow, Geanakoplos, and Klemperer (1985) to refer to games in which the best response functions of the players are upward sloping

${ }^{24}$ In differential terms, this assumption is equivalent to requiring that utility functions be continuously differentiable, with the partial derivative $\partial V_{i} / \partial \hat{c}>0$.
} 
This first part of A6 implies that for a given behavior $\hat{c}$ by other deputies, there is a level of monitoring effort $\tilde{e}(\hat{c})$ above which a deputy's utility is decreasing in his level of corruption. As in section 2.1, let $e=\tilde{e}$ denote the level of monitoring effort sufficient to eliminate corruption at the lower tier. Therefore, if the dictator chooses any level of monitoring $e$ above $\tilde{e}$, the utility of deputy $i$ is decreasing in his level of corruption, regardless of the behavior of other deputies in the economy. The assumption that $\tilde{e}$ is increasing in $\hat{c}$ captures the idea that the level of corruption chosen by deputy $i$ is an increasing function of the behavior of other deputies in the economy. ${ }^{25}$ As a result, for all $x$ and $w$, a higher level of monitoring effort is required to eliminate corruption at the lower tier of the hierarchy.

Let $c_{i}^{*}(\hat{c}, x, w, e)$, denote the best response correspondence of each deputy $i$ to given values of $x, e, w$, and $\hat{c}$. Note that unlike the game in section 2, deputies now take as given the behavior of other deputies in the hierarchy. The following example provides an illustration of assumptions A5 and A6.

Example: Suppose all deputies are risk neutral and have utility functions that are linear in their wage and corrupt incomes. Assume there is a continuum of identical private agents in the economy. For simplicity, suppose that each deputy interacts with a single producer (or investor). Let $x$ denote the return from economic activity for each private agent under the control of a deputy. Each corrupt deputy, then, chooses the amount of economic activity under his control to appropriate for himself. Let $c_{i} x$ denote the corrupt income of each deputy $i$. Assume that each corrupt deputy $i$ faces a probability of arrest which is a function $\left(1-\phi\left(c_{i}, \hat{c}, e\right)\right)$. For simplicity, assume that monitoring effort by the dictator is fixed, so that this variable can be suppressed as an argument in the apprehension function. Let $\phi_{1}>0, \phi_{11}>0$ and $\phi_{2}<0$. Assume that a deputy who is apprehended receives a utility normalized to zero (say, because he is fired). The income of a deputy is therefore $\left(w+c_{i} x\right)$ with probability $1-\phi\left(q_{i}, \hat{c}\right)$ and zero with probability $\phi\left(c_{i}, \hat{c}\right)$. These preferences, together with the probability of arrest function generate deputy $i$ 's payoff function:

$$
V_{i}\left(c_{i}, \hat{c} ; x, w, e\right)=\left(1-\phi\left(c_{i}, \hat{c}\right)\right)\left[c_{i} x+w\right]
$$

Since all agents are identical, we can replace $V_{i}($.$) with V(\cdot)$. Note that $V_{2}(\cdot)=-\phi_{2}\left[c_{i} x+\right.$ $w]>0$ so that the model displays positive spillovers. Differentiating the payoff function with respect to $c_{i}$ and $\hat{c}$ yields

$$
V_{12}=-\phi_{2} x-\phi_{12}\left[c_{i} x+w\right]
$$

\footnotetext{
${ }^{25}$ In general, we can characterize this condition in differential terms for the case of smooth utility functions with Euclidean domains, by requiring that utility functions be twice continuously differentiable with the cross partial derivative $\partial^{2} V / \partial c_{i} \partial \hat{c} \geq 0$. This condition implies that an increase in the level of corruption of all deputies $j$, increases the marginal return to corruption for deputy $i$.
} 
A necessary condition for multiplicity is that $\lambda \geq 1 .^{28}$ Rearranging the above expression, we get

$$
\begin{array}{r}
-\left(\phi_{1}+\phi_{2}\right) x-\left(\phi_{11}+\phi_{12}\left[c_{i} x+w\right]\right) \geq 0 \\
\text { where, } \phi_{1}>0 ; \phi_{2}<0 ; \phi_{11}>0 ; \phi_{12}<0
\end{array}
$$

In terms of the above example, multiple equilibria in corruption are, thus, more likely when the probability of being caught and punished is small, the apprehension function is not very concave with respect to the level of corruption of any given deputy, and when the probability of apprehension faced by a given deputy is sharply decreasing for a higher level of corruption in the economy.

Let $E\left(\Gamma_{s}(e)\right)$ denote the symmetric Nash equilibria of the subgame $\Gamma_{s}(e)$. We now turn to the characterization of the equilibrium set of the whole game. Note that the sequence of actions in this game implies that the dictator can anticipate that there will be multiple Nash equilibria in the subgame. The dictator, therefore, knows the level of lower tier corruption associated with any given level of monitoring effort. Let $\bar{c}=\sup \left\{c^{*}: c^{*} \in E\left(\Gamma_{s}(e)\right)\right\}$ and $\underline{c}=\inf \left\{c^{*}: c^{*} \in E\left(\Gamma_{s}(e)\right)\right\}$ denote the largest and smallest Nash equilibria, respectively, of the subgame. Then $\bar{c}$ and $\underline{c}$ can be regarded as the high corruption and low corruption equilibria of the subgame, respectively.

We now turn to the characterization of the equilibrium set of the whole game. First, note that the sequence of actions in this game implies that the dictator can anticipate that there will be multiple Nash equilibria in the subgame. The dictator, therefore, knows the level of lower tier corruption associated with any given level of monitoring effort. Note that by assumption A6, an increase in monitoring effort does not reduce lower tier corruption to zero as long as $e$ is less than $\tilde{e}$, the minimum level of monitoring effort for which each deputy chooses to be perfectly honest. Therefore, for any change in $e$ such that $e \in(0, \tilde{e}]$, the level of lower tier corruption is unaffected.

In the low corruption equilibrium, the level of monitoring effort chosen by the dictator does not have a significant effect on the level of lower tier corruption. By definition 3.1 , the payoff attainable to a deputy from choosing a level of corruption $\underline{c}$ in the low corruption equilibrium exceeds the payoff from any other alternative. An increase in monitoring effort decreases a deputy's payoff from corruption, but for any $\subseteq$ close to zero, has no significant effect on the level of corruption at the lower level of the hierarchy. Given that $U(\cdot)$ is increasing in $e$, for all $w$ and $\tau$, in a low corruption equilibrium the dictator, therefore, has an incentive to chose the lowest level of monitoring effort such that $c^{*}=\underline{c}$.

In the high corruption equilibrium, the level of monitoring effort chosen by the dictator affects the level of lower tier corruption. Increasing monitoring effort decreases a deputy's

\footnotetext{
${ }^{28} \mathrm{~A}$ sufficient condition for multiple equilibria in this environment is that $\lambda>1$.
} 
A necessary and sufficient condition for strategic complementarity in this environment is that $\phi_{12}<0 .{ }^{26}$ This example shows that the expected utility to a deputy $i$ from corruption increases as more deputies in the hierarchy are corrupt (positive externality), and a higher level of corruption in the hierarchy increases the profitability of engaging in corrupt acts, so deputy $i$ will increase $c_{i}$ (strategic complementarity).

In this example, the strategic complementarity arises because the greater the average level of corruption in the economy, a given increase in $c_{i}$ is assumed to decrease the probability with which a given deputy is apprehended. ${ }^{27}$

Let $\Gamma^{*}=\Gamma^{*}\left(X, U, V_{i \in[0,1]}\right)$ define a game in this environment. The equilibrium notion we use is that of a subgame perfect Nash equilibrium. A subgame perfect Nash equilibrium can be defined as a behavior strategy combination of each agent such that the behavior strategy of each player is a best response strategy against the behavior strategies of the other agents in every subgame. In this game, the subgame consists of the second-stage interaction between deputies given the policy actions taken by the dictator in the first stage of the game.

Let $\Gamma_{s}(e)$ denote the subgame of this game, where the subgame depends on the level of monitoring chosen by the dictator in the first stage of the game for a given $w$ and $\tau$. For a given $e$, if the vector $\left.c_{i}^{*}, \hat{c}\right)_{i \in[0,1]}$ is to be a Nash equilibrium of $\Gamma_{s}(e)$ then, for each $i$, if all other deputies are choosing an action $c$, it is in the interest of the remaining agent to choose $c$ as well. Under relatively simple assumptions, the game only has symmetric Nash equilibria.

Assumption A 7. $\Gamma_{s}(e)$ has multiple symmetric Nash Equilibria.

In general, a necessary condition for multiple equilibria is upward sloping reaction functions for agents, a condition which is satisfied by our assumption of strategic complementarity. In terms of our earlier example, let $\lambda$ denote the slope of deputy $i$ 's reaction function.

$$
\lambda=\frac{-V_{12}}{V_{11}}=\frac{-\phi_{2} x-\phi_{12}\left[c_{i} x+w\right]}{\phi_{11}\left[c_{i} x+w\right]+2 \phi_{1} x}>0
$$

\footnotetext{
${ }^{26}$ Note that this is a necessary as well as sufficient condition because the deputy's utility function is assumed to be linear. For more general utility functions, additional restrictions may be required for increases in $\hat{c}$ to induce increases in $c_{i}$.

${ }^{27}$ Note that the strategic complementarity in the above example depends on the implicit assumption that corrupt deputies do not crowd each other by competing for the proceeds from private sector activity. In reality, the return from corruption may actually fall if a higher level of corruption in the hierarchy implies a lower return per corrupt deputy. In the example above, we avoid this property of crowding by assuming that each deputy interacts with a single producer or investor.
} 
payoff from corruption for any given behavior of other deputies in the hierarchy, and thus decreases the level of corruption in the hierarchy. By assumption A6, however, for all $x$ and $w$ and $\hat{c}=\bar{c}$, a sufficiently high level of monitoring effort is required to eliminate corruption at the lower tier of the hierarchy. If $U(\cdot)$ is sharply increasing in monitoring effort, in a high corruption equilibrium, the dictator has an incentive to choose a level of monitoring effort such that $c^{*}=\bar{c}$.

Let $\underline{e}$ and $\ddot{e}$ define the smallest and the largest levels of monitoring effort of the dictator such that deputies choose a low or high level of corruption, respectively, for all $w$ and $\tau$.

\section{Definition 6.}

$$
\begin{aligned}
& \underline{e} \equiv \inf \left\{e: \forall(w, \tau), c^{*}\left(e, w, x^{*}\right)=\underline{c}, x^{*}=x^{*}(\tau, \underline{c})\right\} \\
& \bar{e} \equiv \sup \left\{e: \forall(w, \tau), c^{*}\left(e, w, x^{*}\right)=\bar{c}, x^{*}=x^{*}(\tau, \bar{c})\right\}
\end{aligned}
$$

The following lemma characterizes the equilibrium precommittment of monitoring effort by the dictator in the presence of the strategic complementarity between deputies.

\section{Lemma 2.}

(1) If $c^{*}=\underline{c}$ in equilibrium, then $e^{*}=\underline{e}$

(2) If $c^{*}=\bar{c}$ in equilibrium, then $e^{*}=\bar{e}$

Proof: Follows from assumption A6, the definition of a subgame perfect equilibrium, and definition 3.2 .

Condition (i) states that if the economy is in a low corruption equilibrium, the optimal level of monitoring effort chosen by the dictator must be sufficient to ensure that deputies choose a $\underline{c} \in E\left(\Gamma_{s}(e)\right)$. Similarly, condition (ii) states that if a high corruption equilibrium obtains, the dictator must be choosing a level of monitoring effort such that $\bar{c} \in E\left(\Gamma_{s}(e)\right)$. Note that in both instances, the dictator has to commit to a positive amount of monitoring effort. An important implication of this lemma is that the level of private sector activity in a low corruption equilibrium will be higher than that in a high corruption equilibrium. This implication follows directly from assumption A3, which states that the level of private sector activity is decreasing in the level of corruption in the government.

In general, the set of equilibria for the entire game depend on the dictator's utility function $U$, and a mapping $M: e \mapsto E\left(\Gamma_{s}(e)\right)$. Formally,

Definition 7. A subgame perfect equilibrium for $\Gamma^{*}\left(X, U, V_{i \in[0,1]}\right)$ is a quintuple $\left(e^{*}, w^{*}, \tau^{*}, c^{*}, x^{*}\right)$ and a mapping $M: e \mapsto M\left(e \in E\left[\Gamma_{s}(e)\right]\right)$ such that

1. $x^{*}=x^{*}\left(c^{*}, \tau^{*}\right)$,

2. $c^{*}=c^{*}\left(x^{*}, M(e), w^{*}\right)$,

3. $\left(w^{*}, e^{*}, \tau^{*}\right) \in \arg \max _{w, e, \tau} U\left(w, e, \tau, x^{*}\right)$. 
The following observation states the main result of this section.

Observation 1. Depending on $M(e)$ and $U(\cdot), \Gamma^{*}\left(X, U, V_{i \in[0,1]}\right)$ may have multiple Nash equilibria.

This observation states that in the presence of the strategic complementarity between deputies, there may be multiple Nash equilibria in the whole game. This multiplicity of equilibria suggests that even with endogenous monitoring, identically endowed economies can end up in very different equilibria. One can have high corruption and a low level of private sector activity, while the other can have a low level of corruption in the government hierarchy and a high level of economic activity. Note, however, that if the dictator chooses a level of monitoring effort $e=\tilde{e}$, the game has a unique equilibrium with perfect honesty at the lower tier of the government hierarchy. Through sufficient monitoring effort, therefore, an economy can move from a high corruption equilibrium to an equilibrium with no corruption.

The existence of an equilibrium with a perfectly honest lower tier, however, depends on whether the benefits of eradicating corruption exceed the costs. In general, if monitoring costs are sharply increasing in monitoring effort, the monitoring technology is inefficient and the level of economic activity is not very responsive to lower level corruption, then the optimal level of corruption in the economy will not be zero.

\section{CONCLUSION}

This paper has attempted to explain the observable variation in the nature and level of corruption both across countries and across time by analyzing the strategic interactions between self-interested agents that compose the state. We have shown that the selfinterested behavior of central authorities determines the optimal level of corruption in the hierarchy. Our analysis also highlights factors that could lead authorities to choose policy instruments that allow lower tier corruption. In particular, we have shown that an equilibrium with corruption arises when a central authority chooses not to make a commitment to monitoring deputies.

This paper also provides important implication about the relationship between monitoring and the provision of wage incentives. We have shown that in the presence of poor and ineffective monitoring, it may be optimal for a central authority to allow corrupt lower tier activities as a means of economizing on the costs of providing wage incentives. An important implication of this result is that in economies with high levels of corruption, we may expect to observe low public sector wages coexisting with weak monitoring. This prediction is borne out by observations for many developing countries. Our analysis also brings out the factors that could lead central authorities to choose the sale of offices or tax farming as a form of agency.

The tradeoff between the reduction in corruption and the higher fiscal costs of Providing appropriate wage incentives is likely to be higher in developing and transition economies. 
More generally, large and bloated bureaucracies can substantially increase the cost of providing proper wage incentives. An important policy implication of these results is that to the extent that providing wage incentives is costly, this measure should be considered as part of general civil service reform effort, which involves a combination of civil service restructuring, increase in salaries, as well as measures to strengthen institutional controls. The latter include enforcing standards for ethical behavior, improvements in accounting and auditing practices, and transparent and well-defined rules, laws, and processes.

Finally, we have shown that in the presence of strategic interactions between deputies, even with endogenous monitoring, countries in very similar circumstances can end up with widely different outcomes. We show that only through sufficient monitoring can an economy move from a high corruption equilibrium to a low corruption one. From a policy perspective, the existence of two stable equilibria in corruption implies that ad hoc anti corruption campaigns have little effect on the level of corruption in an economy. For anti corruption policy to be effective, it must, therefore, be sustained.

An added implication of this paper is that providing appropriate incentives to central authorities may ensure the existence of low corruption equilibrium. For instance, a high corruption equilibrium is characterized with a low level of private sector activity, thereby signifying low tax revenues for the central authority. If higher levels of economic activity push a self-interested authority to its most profitable equilibrium, it is more likely to adopt monitoring policies and wage incentives that reduce or even eliminate lower tier corruption. More importantly, an environment that promotes political competition and relates the probability of being reelected to the level of corruption in society can serve as important incentives for central authorities to adopt policies that control corruption and promote economic growth. Therefore, measures that eliminate discretionary elements of government policy, strengthen the rule of law, including setting up an independent and impartial judicial system, and enhancing the transparency and accountability of government actions, can serve as important deterrents to corruption. 


\section{References}

Andvrig, J., and K. Moene, 1990, "How Corruption May Corrupt," Journal of Economic Behavior and Organization, Vol. 13, pp. 63-76.

Banerjee, A.V., 1997, “A Theory of Misgovernance," Quarterly Journal of Economics, Vol. 112, pp. 1289-332.

Bardhan, P., 1990, "Symposium on the State and Economic Development," Journal of Economic Perspectives, Vol. 4, pp. 3-7.

Besley, T., and J. McLaren, 1993, “Taxes and Bribery: The Role of Wage Incentives," The Economic Journal, Vol. 103, pp. 119-41.

Bulow, J., J. Geanakoplos, and P. Klemperer, 1985, "Multimarket Oligopoly: Strategic Substitutes and Complements," Journal of Political Economy, Vol. 93, pp. 488-511.

Cadot, O., 1987, "Corruption as a Gamble," Journal of Public Economics, Vol. 33, pp. 223-44.

Carillo, J.D., 1995, "Grafts, Bribes and the Practice of Corruption,"(mimeo; Toulouse: GREMAQ).

Dabla-Norris E., and S. Freeman, 1999, “The Enforcement of Property Rights and Underdevelopment," IMF Working Paper 99/127 (Washington: International Monetary Fund).

Evans, P., 1989, "Predatory, Developmental, and Other Apparatuses: A Comparative Political Economy Perspective on the Third World State," Sociological Forum, Vol. 4 (December), pp. 561-87.

Freeman, S., Grogger, and J. Sonstelie, 1996, "The Spatial Concentration of Crime in Underclass Neighborhoods," Journal of Urban Economics, Vol. 40, pp. 216-31.

Gibbons, R.G., 1992, Game Theory for Applied Economists (Princeton: Princeton University Press).

Gould, D.J., 1980, Bureaucratic Corruption and Underdevelopment in the Third World: The Case of Zaire (New York: Pergamon Press).

, and J.A. Amaro-Reyes, 1983, "The Effects of Corruption on Administrative Performance: Illustrations from Developing Countries," World Bank Staff Development Report No. 580 (Washington: World Bank).

Klitgaard, R., 1988, Controlling Corruption (Berkley: University of California Press). 
Keefer, P., and S. Knack, 1997, "Why Don't Poor Countries Catch Up? A Cross-National Test of an Institutional Explanation," Economic Inquiry, Vol. 35, pp. 590-602.

Krueger, A.P., 1974, "The Political Economy of a Rent-Seeking Society," American Economic Review, Vol. 64, pp. 291-303.

Levi, M., 1988, Of Rule and Revenue (Berkley: University of California Press).

Lui, F., 1986, “A Dynamic Model of Corruption Deterrence," Journal of Public Economics, Vol. 31, pp. 215-36.

Mauro, P., 1995, "Corruption and Growth," Quarterly Journal of Economics, Vol. 110, pp. $681-712$.

Milgrom, P., and J. Roberts, 1990, "Rationalizability, Learning and Equilibrium in Games. With Strategic Complementarities," Econometrica, Vol. 58, pp. 1255-78.

Mookherji, D., and I.P.L. Png, 1995, "Corruptible Law Enforcers: How Should They be Compensated?" The Economic Journal, Vol. 105, pp. 145-59.

Murphy, K., A. Schliefer, and R. Vishny, 1993, "Why Is Rent-Seeking so Costly to Growth?" American Economic Review, Vol. 83, pp. 409-14.

North, D.C., 1990, Institutions, Institutional Change and Economic Performance (Cambridge: Cambridge University Press).

Olson, M., 1991, “Autocracy, Democracy, and Prosperity,” in Strategy and Choice, ed. by Richard J. Zeckhauser, pp. 131-57 (Cambridge, Massachusetts: MIT Press).

Rauch, J.E., 1995, "Choosing a Dictator: Bureaucracy and Welfare in Less Developed Polities," NBER Working Paper No. 5196 (Cambridge, Massachusetts: National Bureau of Economic Review).

Rose Ackerman, S., 1978, Corruption: A Study in Political Economy (New York: Academic Press).

Shliefer, A., and R. Vishny, 1993, "Corruption," Quarterly Journal of Economics, Vol. 108 (August), pp. 599-617.

Srinivasan, T.N., 1985, "Neoclassical Political Economy, the State and Economic Development," Asian Development Review, Vol. 3, pp. 38-58.

Tanzi, V., 1998, "Corruption Around the World: Causes, Consequences, Scope, and Cures," IMF Working Paper 98/63, (Washington: International Monetary Fund). 
Tirole, J., 1993, A Theory of Collective Reputations with Applications to the Persistence of Corruption and to Firm Quality (Manuscript; Toulouse: Institut d'Economie Industrielle).

van Rijckeghen, and B. Weder, 1997, "Corruption and the Rate of Temptation: Do Low Wages in the Civil Service Cause Corruption?" IMF Working Paper 97/73 (Washington: International Monetary Fund).

Topkis, D., 1978, "Minimizing a Supermodular Function on a Lattice," Operations Research, Vol. 26, pp. 305-21. 